\title{
Wildlife cameras effectively survey Black Grouse Lyrurus tetrix leks
}

\section{Håkon Gregersen ${ }^{1} \&$ Finn Gregersen ${ }^{2}$}

${ }^{1}$ Sweco Norge AS, P.O. Box 400, N-1327 Lysaker, Oslo, Norway; e-mail: Hakon.Gregersen@sweco.no

${ }^{2}$ Aage Håkonsens vei 1D, N-3610 Kongsberg, Norway; e-mail: finngreger@yahoo.no

\begin{abstract}
Within the fields of behavioral ecology, population ecology and wildlife management, Black Grouse Lyrurus tetrix is of special interest, as it is a promiscuous, polygamous and lekking game species. In 2011 and 2012 we surveyed six leks in Eastern Norway with wildlife cameras. Here, we show how wildlife cameras can ease data sampling on leks and give us good data on numbers and temporal patterns of visits. Wildlife cameras allow continuous sampling of large amounts of data for long time periods but may underestimate actual visit percent. Our results show that Black Grouse males visit leks most of the year. The fact that we may underestimate actual visit percent means that leks could be even more important than our data suggest.
\end{abstract}

Keywords: wildlife-surveillance, grouse, lek visits

\section{INTRODUCTION}

Within the fields of behavioral ecology, population ecology and wildlife management, Black Grouse Lyrurus tetrix is of special interest, as it is a promiscuous, polygamous and lekking game species (Baines 1990; Swenson \& Angelstam 1993; Höglund \& Alatalo 1995; Alatalo et al. 1996; Rintamäki et al. 1999; Lüdwig et al. 2006; Höglund et al. 2007). Bogs and mires are key habitats for Black Grouse throughout its life-cycle (Baines 1990; Lüdwig et al. 2006, 2008). Lekking occurs in April and May on display arenas established on open, large mires. Here, lekking males display to attract and mate with hens attracted to the lek. They fight for and defend small territories, and finally attract hens to be courted (Höglund \& Alatalo 1995; Rintamäki et al. 1999).

Lek systems are especially interesting study objects, but to achieve powerful statistical material, when a study calls for many populations with enough individual males, has traditionally been difficult due to limitations in personnel, time and other resources. In wildlife surveillance, wildlife cameras have successfully been used for many species and would probably function well on Black Grouse leks too (Swann et al. 2004; Demers \& Robinson-Nilsen 2012; Dougherty \& Bowman 2012).

Wildlife cameras have the potential to ease research on Black Grouse leks due to the large increase in data sampling capacity, detectability of different behavior, and the ability of avoiding disturbance from human observers (O'Connell et al. 2011; Hamel et al. 2013).
However, to our knowledge, no prior scientific studies have used wildlife cameras for continuous standby data sampling at leks throughout the annual cycle. Since the cost of high quality wildlife cameras has decreased dramatically, it opens up the possibilities for this new observational technique. The alternative, manual observation of leks, is labour intensive, and several observers are required to obtain data from different leks at the same time (Hjort 1968, 1970).

The main aim of this study was to test wildlife cameras for data sampling at leks. Particularly, we were interested in number of visits by Black Grouse males per time unit and their seasonal visit frequency. We present data from surveying six leks in 2011 and 2012 and we discuss whether wildlife cameras are effective in surveying leks regularly, and also for quantifying the use of leks through the annual cycle.

\section{MATERIAL AND METHODS}

Six leks were selected for this study situated in Eastern Norway, of which four were surveyed with daycameras and two with night-cameras (takes pictures both day and night). Descriptive statistics for the individual leks in this study is presented in Table 1. All leks were situated centrally on a mire within typical boggy, thinly spruced landscapes. They were surveyed within different periods from April 2011 to December 2012. Hamar, Elverum and Tinn were surveyed only in 2012 and the two first with night-cameras. Cameras covered all the display arenas that were verified by 


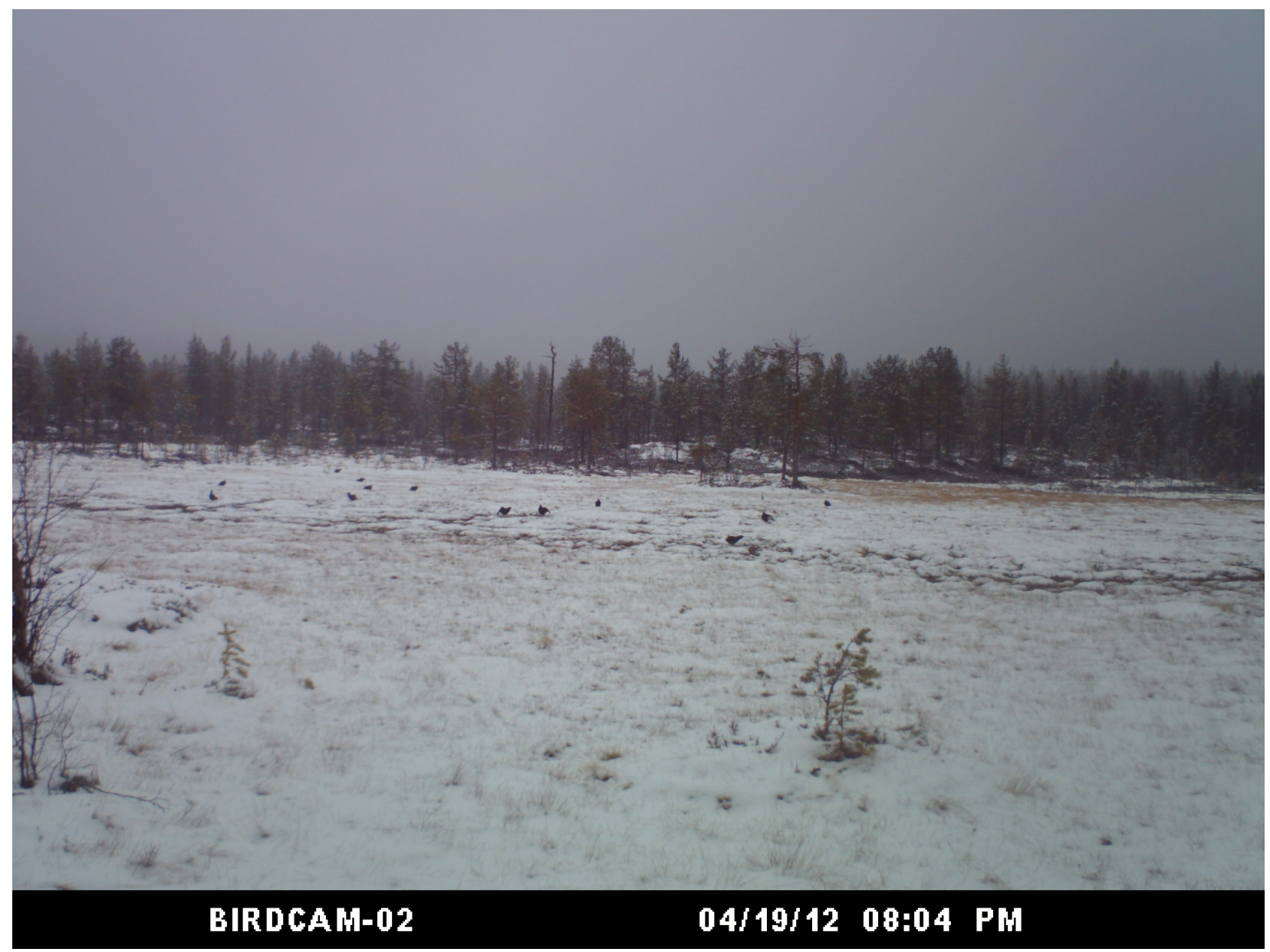

Figure 1. Example picture from the Kongsberg lek.

long-term monitoring of the leks looking for visual signs, such as eroded vegetation, faeces and feathers (Figure 1, unpublished data). Number of pictures taken varied from 5704 in Hamar to 23014 in Røyken. Picture analysis (counting of birds) was done manually by one trained analyst (H. Gregersen). Number of pictures with birds varies from 130 in Liset to 833 in Hamar. Tinn, Kongsberg, Fet and Røyken were all recorded with day-cameras.

We used two camera types, Acorn Ltl model 5210A and the Wingscapes Birdcam model 2.0, both with a passive infrared (PIR) sensor and a time-lapse function that trigger exposures. For our purpose, only the timelapse function was used, as we had to gain distance to include the total lek area in each exposure. All cameras were set 50-120 meters from the lek center to cover all the lek area (Figure 1). Both cameras functioned properly between $-25^{\circ}$ and $+25^{\circ}$ Celsius. The battery had to be changed every third month.

The Acorn Ltl 5210A model works with the PIR sensor active in time-lapse mode (http://www.ltlacorn. $\mathrm{com} /$ ). The model is equipped with a 5 mega pixel colour CMOS (complementary metal-oxide semi-conductor) image sensors. The lens is a multi-element glass lens with fixed aperture at F/3.1. The interval of the time- lapse was set to trigger each 20 minutes. The camera works with an infrared flash and can thus operate day and night, giving approximately 72 pictures each day.

The Wingscapes Birdcam 2.0 w/flash (www. wingscapes.com/support) was set to time-lapse mode. In this mode the PIR is not activated. The model is equipped with an 8 mega pixel color CMOS and the lens is a multi-element glass lens with fixed aperture at $\mathrm{F} / 2.8$. The camera was set to take pictures at intervals of 20 minutes. When light conditions exceed 12.5 lumen the camera works with flash. However, to not disturb wildlife we deactivated the flash. The camera takes 15 to 50 pictures a day, less in winter and more in summer.

Frequencies of Black Grouse use of leks as per cent of days with visits in weekly and seasonal intervals were calculated (the visit percent). The lack of temporal overlap in time series among leks (uneven sampling design) and low sample size when splitting on cameras make testing of comparisons among leks and camera types inappropriate.

\section{RESULTS}

The mean number of birds in a picture was highest at 
Table 1. Descriptive statistics for the six leks used in this study in Eastern Norway.

\begin{tabular}{|c|c|c|c|c|c|}
\hline Lek site & $\begin{array}{l}\text { Period of } \\
\text { surveillance } \\
\text { (dd.mm.yyyy) }\end{array}$ & Camera type & $\begin{array}{l}\text { Number of } \\
\text { pictures taken } \\
\text { on the lek }\end{array}$ & $\begin{array}{l}\text { Number of } \\
\text { pictures } \\
\text { with birds }\end{array}$ & $\begin{array}{l}\text { Mean number } \\
\text { of birds on } \\
\text { pictures } \pm \mathrm{SE}\end{array}$ \\
\hline Fet & $\begin{array}{r}25.08 .2011- \\
02.11 .2012\end{array}$ & Day & 14717 & 430 & $3.11 \pm 0.12$ \\
\hline Elverum & $\begin{array}{r}23.03 .2012- \\
30.06 .2012\end{array}$ & Day-night & 7058 & 766 & $5.92 \pm 0.09$ \\
\hline Kongsberg & $\begin{array}{r}18.06 .2011- \\
31.12 .2012\end{array}$ & Day & 21178 & 823 & $7.53 \pm 0.09$ \\
\hline Tinn & $\begin{array}{l}27.04 .2012- \\
\quad 18.10 .2012^{*}\end{array}$ & Day & 6380 & 130 & $1.52 \pm 0.22$ \\
\hline Røyken & $\begin{array}{l}27.04 .2011- \\
\quad 30.12 .2012\end{array}$ & Day & 23014 & 354 & $4.23 \pm 0.13$ \\
\hline Hamar & $\begin{array}{r}30.03 .2012- \\
19.06 .2012\end{array}$ & Day-night & 5704 & 833 & $4.23 \pm 0.09$ \\
\hline
\end{tabular}

*27.05-13.09 camera failure

Kongsberg and lowest at Tinn (Figure 2, Table 1). The wildlife cameras in our study documented that Black Grouse visit frequencies on leks were high throughout the year with a peak in spring and autumn (Figure 3). The periods with the lowest number of visits were midsummer and mid-winter. In May, the main visit time is from 5.00-7.00 and in winter from 10.00-12.00, but visits are spread throughout day and night in May. Night visits are barely recorded by the day-cameras, but well recorded by night-cameras (Figure 3). The time of visits shows a marked trend towards later appearance in autumn/winter and opposite during spring.

Overall, visit percent is highest in spring, lower in autumn and winter and lowest in summer (Table 2). No visits were recorded at any of the leks during a few weeks in late June to early July (Figure 3, 4). Visit percent for the individual leks show the same pattern that birds visit leks almost throughout the year. However, around week 23-25 leks are abandoned for several weeks until autumn (week 30-33) (Figure 4). Weeks of no visits range from 1 out of 14 in Elverum to 22 out of 52 in Røyken (Table 2).

\section{DISCUSSION}

This study shows that modern wildlife cameras are suitable for effective sampling of data on Black Grouse leks. Compared to traditional observational methods, massive amounts of data can easily be collected
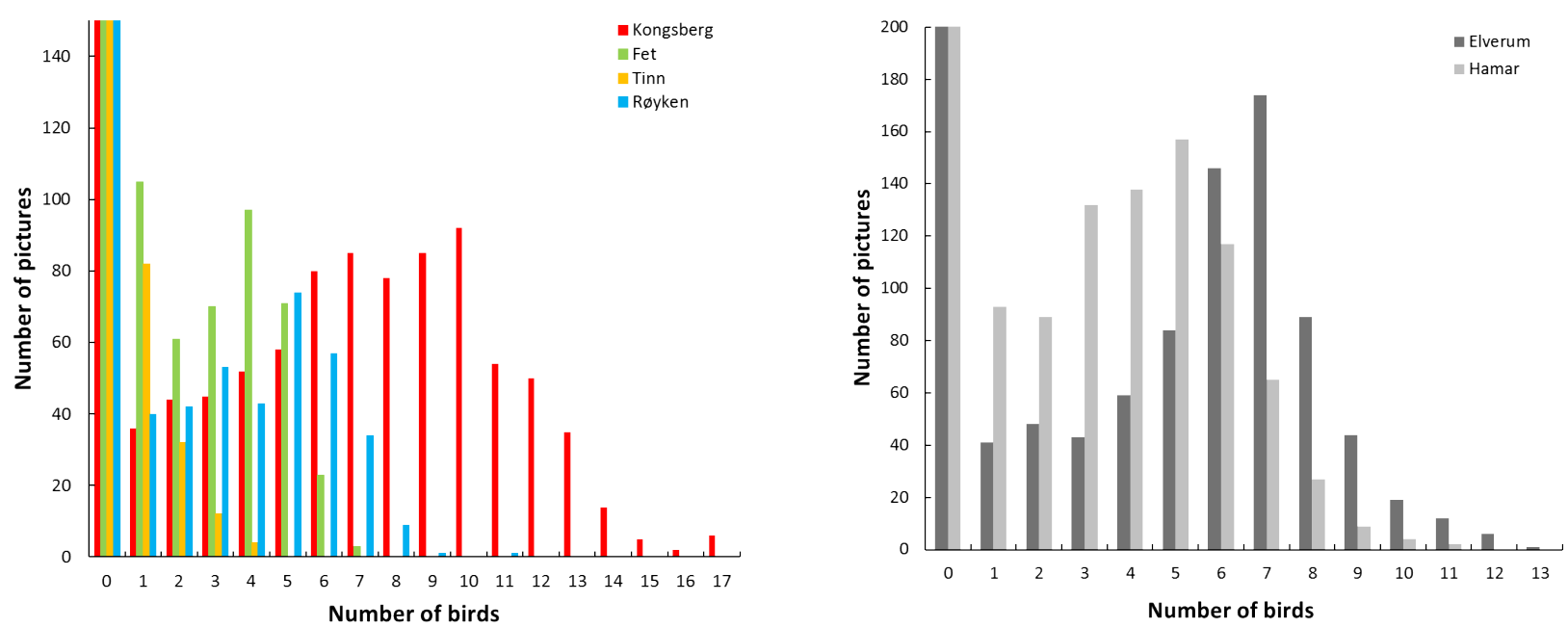

Figure 2. Distributions of pictures taken on the six leks from (a) day-cameras and (b) night-day-cameras. The 0-category (pictures with no bird records) are presented with cut columns in the histogram (numbers available from Table 1). 


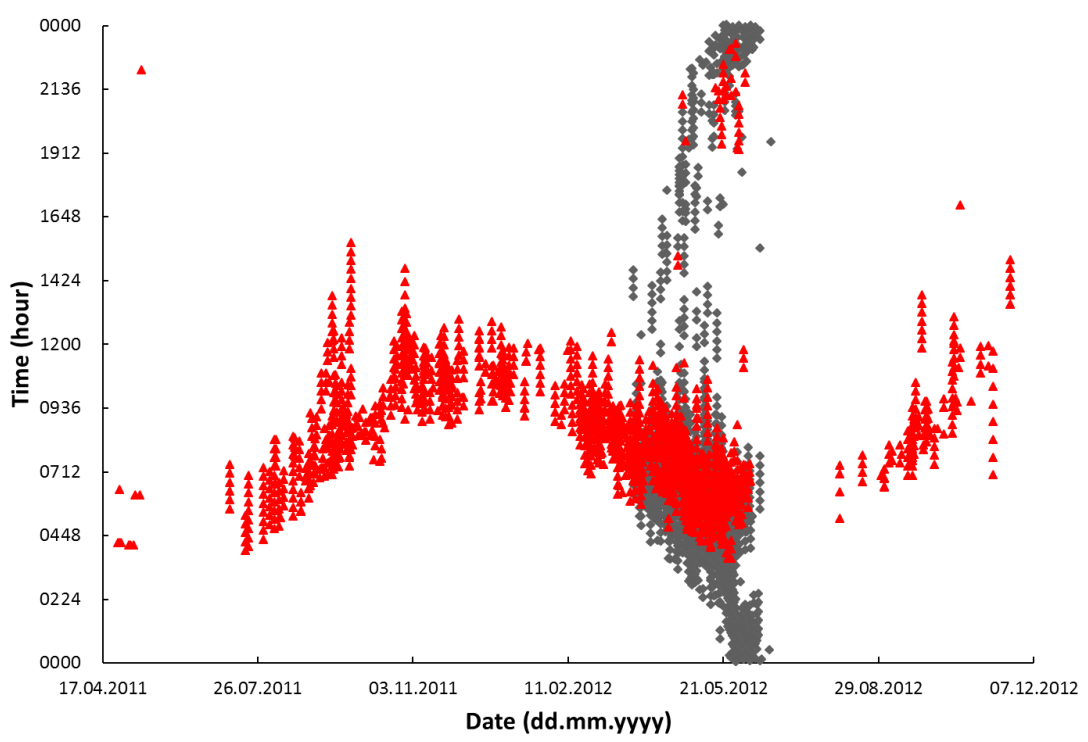

Figure 3. Visit time and date for pooled data from night (grey symbols) and day (red symbols) cameras.

over long periods of time. We describe temporal and numerical data and particularly discuss why Black Grouse males visit leks most of the year. Our study shows that wildlife cameras surveying Black Grouse leks have great potential, and as long as study design principles are followed this method is precise (Hamel et al. 2013). Camera and data technology have gone through an immense evolution with respect to size, storage capacity, costs and technical solutions (Harris et al. 2010; O'Connell et al. 2011). Wildlife cameras are already extensively used in various animal studies, for instance on animal trails recording any passing object or surveys of predators robbing nests or feeding on carcasses (Jahren 2012; Hamel et al. 2013). To carry out these sort of studies with personnel had been difficult because of the risk of influencing Black Grouse behavior and high cost of labour intensive work. Hjort $(1968,1970)$ spent hundreds of days in a shelter over several years observing Black Grouse behavior and had control over just a few leks. Visits on snow had given accumulated signs of visits on a much coarser time-scale and not as a precision-material (as for Capercaillie Tetrao urogallus lek activity Gregersen \& Gregersen (2008)).

As our day-cameras are shut off until light intensity reaches 12.5 lux they may underestimate actual visit percent. Hjorth (1968) documented first arriving males in spring at civil twilight (3.4 lux) meaning that there is a time gap where our day-cameras do not capture males at the lek. Comparison between camera types confirms that day-cameras miss the earliest visits of Black Grouse. The time gap in the morning from 0-12.5 lux is 20-30 minutes, depending on weather, latitude and topography. However, as long as the males stay on the lek towards sunrise they will be recorded by our daycameras and this type of underestimation will be minor. Further, under-estimation of visits occurs for both camera types because birds can visit the lek between the 20 minute picture intervals. This under-estimation is especially important in low-frequency periods when visits are short and rare. We have no data yet for estimating the likelihood of discovering birds when they only visit leks at short intervals with different time-lapse periods, which would require series of

Table 2. Summary of visit percent for the six leks in this study. Visit percent is the percentage of days in a given time period (a week or a season) where birds were recorded. Autumn is defined as September to November, winter as December to February, spring as March to May and summer as June to August. No value means that surveillance has not occurred in that period.

\begin{tabular}{llllll}
\hline Lek site & $\begin{array}{l}\text { Weeks with } \\
\text { zero visit }\end{array}$ & \multicolumn{4}{c}{ Mean visit percent (\% days) } \\
\cline { 3 - 5 } & percent & Spring & Summer & Autumn & Winter \\
\hline Fet & 17 of 52 & 41.3 & 5.1 & 21.4 & 33.0 \\
Elverum & 1 of 14 & 97.1 & 65.4 & No value & No value \\
Kongsberg & 9 of 52 & 80.4 & 18.4 & 38.5 & 12.3 \\
Tinn & 3 of 11 & 75.9 & No value & 19.4 & No value \\
Røyken & 22 of 52 & 41.3 & 2.2 & 16.5 & 9.8 \\
Hamar & 1 of 13 & 100 & 73.7 & No value & No value \\
\hline
\end{tabular}




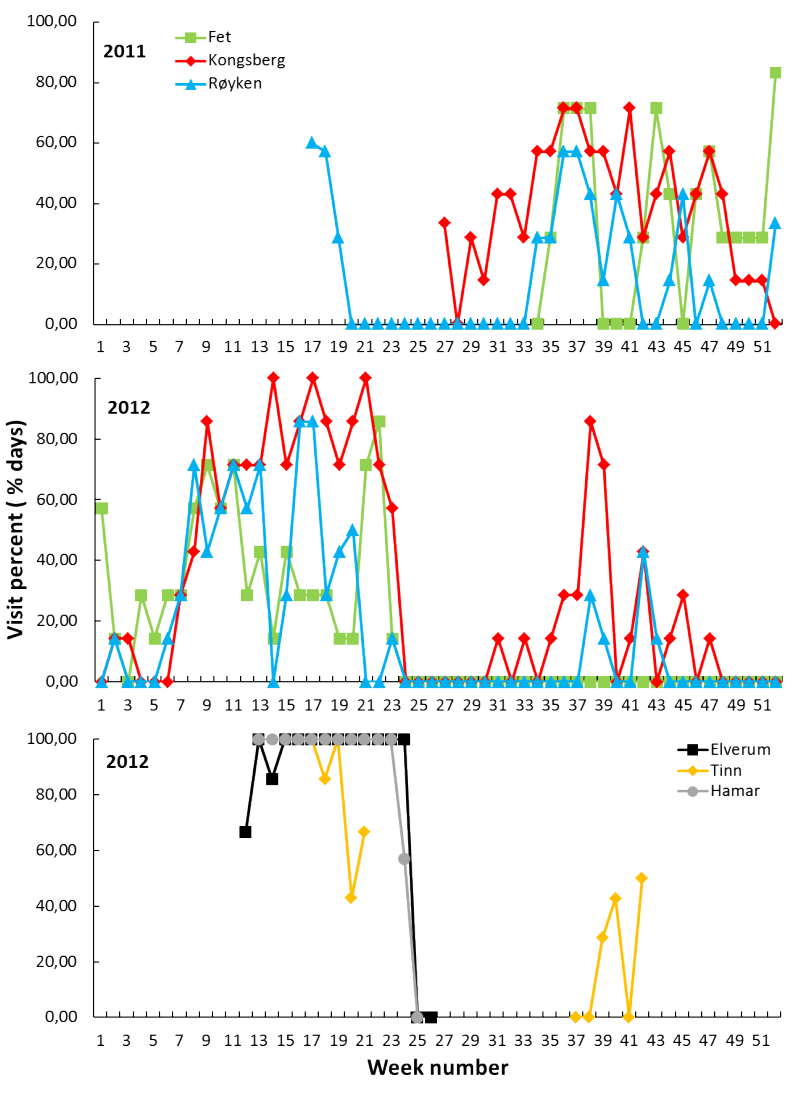

Figure 4. Visit percent (\% days) for the individual leks in 2011 and 2012. Coloured symbols represent day-cameras, whereas black and grey represent night-cameras.

photos taken at shortest possible intervals to calculate hypothetical visit percent for longer time-lapse periods (see Hamel et al. 2013 for a thorough treatment of this topic). These weaknesses are easily solved by shorter time-lapse intervals or using cameras which have night vision or do not shut off at low light intensity.

Using wildlife cameras indicated that leks are visited by Black Grouse males year-round as previously documented by Hjorth (1968). This is explained by the fact that males have to fight continuously for a position in the flock each day to establish dominance hierarchies and fight for the hottest spot on the lek (Kokko et al. 1998). Further, two periods are especially marked, the lekking season peaking in May, and when youngsters (i.e. new competitors) are introduced to the seniors in autumn (peaking in October). This interaction and competition for space on a lek in spring and autumn is documented in previous studies (Alatalo et al. 1992, 1996; Høglund \& Alatalo 1995; Rintamäki et al. 1999; Siitari et al. 2007), but our study is the first verifying its magnitude using wildlife cameras and giving fineresolution quantitative data on numerical and temporal data year-round.

Decline in Black Grouse populations has occurred all over Europe in the last 50 years (Kurki et al. 2000;
Lüdwig et al. 2008; Gregersen \& Gregersen 2009). Drainage of mires and wet forest influences the most optimal foraging sites for Black Grouse, which probably partly explains population declines, together with climatic factors (Hanski \& Walsch 2004; Lüdwig 2007; Kausrud et al. 2008). Our study is highly relevant for Black Grouse management since we now show that Black Grouse spend so much time on these same areas as lekking grounds. Leks are key-habitats used throughout season for foraging, lekking and socialization. Wildlife cameras can cost-effectively monitor populations as long as the whole regional lek structure is under control (movement of individuals within the metapopulation). We detected differences among leks and seasons in numbers and visit percent. Therefore this surveillance method is particularly relevant for nature management and may be implemented in standard wildlife surveillance.

Acknowledgements. We thank Jørn Sagstuen for participating in field work and Olav Hjeljord and Kjetil Flydal giving valuable comments on earlier versions of this manuscript.

\section{REFERENCES}

Alatalo, R.V., Höglund, J. \& Sutherland, W.J. 1992. Evolution of Black Grouse leks: female preferences benefit males in larger leks. Behavioral Ecology 3: 53-59.

Alatalo, R.V., Höglund, J., Lundberg, A., Rintamäki, P.T. \& Silverin, B. 1996. Testosterone and male mating success on black grouse leks. Poceedings of Royal Society of London B 263: 1697-1702.

Baines, D. 1990. The ecology and conservation of black grouse in Scotland and northern England. In: Lumeij, J.T. \& Hoogeveen, Y.R. (eds.) The future of wild galliformes in the Netherlands: 106-118. Organisatiecommissie Nederlandse Wilde Hoenders, Amersfoort.

Demers, S.A. \& Robinson-Nilsen, C.W. 2012. Monitoring western Snowy Plover nests with remote surveillance systems in San Fransisco Bay, California. Journal of Fish and Wildlife Management 3: 123-132.

Dougherty, S.Q. \& Bowman, J.L. 2012. Estimating sika deer abundance using camera surveys. Population Ecology 54: $357-365$.

Gregersen, F. \& Gregersen, H. 2009. Ongoing population decline and range contraction in Norwegian forest grouse. Ornis Norvegica 32: 170-180.

Gregersen, H. \& Gregersen, F. 2008. Old bilberry forest is a key indicator of Capercaillie (Tetrao urogallus) lek size and presence. Ornis Norvegica 31: 109-119.

Hamel, S., Killengreen, S.T., Henden, J.-A., Eide, N., RoedEriksen, L., Ims, R.A. \& Yoccos, N.G. 2013. Towards good practice guidance in using camera-traps in ecology: influence of sampling design on validity of ecological inferences. Methods in Ecology and Evolution 4: 105-113. 
Hanski \& Walsch 2004. How much, how to? Practical tools for forest conservation. Birdlife International, Helsinki.

Harris, G., Thompson, R., Childs, J.L. \& Sanderson, J.G. 2010. Automatic storage and analysis of camera trap data. Bulletin of the Ecological Society of America 91: 352-360.

Hjorth, I. 1968. Significance of light in the initiation of morning display of the Black Grouse. Viltrevy 5: 39-94.

Hjorth, I. 1970. Reproductive behavior of Tetraonidae with special reference to males. Viltrevy 7: 184-596.

Höglund, J. \& Alatalo, R.V. 1995. Leks. Princeton University Press, Princeton.

Höglund, J., Larsson, J.K., Jansman, H.A.H. \& Segelbacher, G. 2007. Genetic variability in European Black Grouse (Tetrao tetrix). Conservation Genetics 8: 239-243.

Jahren, T. 2012. Nest predation in Capercaillie and Black Grouse. Master thesis at Faculty of Applied Ecology and Agricultural Sciencis, Hedmark College.

Kausrud, K., Mysterud, A., Steen, H., Vik, J.O., Østbye, E., Caselles, B., Framstad, E., Eikeset, A.M., Mysterud, I., Solhøy, T. \& Stenseth, N.C. 2008. Linking climate change to lemming cycles. Nature 456: 93-97.

Kokko, H., Lindström, J., Alatalo, R.V. \& Rintamäki, P.T. 1998. Queuing for territory positions in the lekking Black Grouse (Tetrao tetrix). Behavioral Ecology 9: 376-383.

Kurki, S., Nikula, A., Helle, P., Lindén, H. 2000. Landscape fragmentation and forest composition effects on grouse breeding success in boreal forests. Ecology 81: 1985-1997.

Lüdwig, G.X. 2007. Mechanisms of population declines in Boreal forest grouse. PhD dissertion. University of Jyväskylä, Jyväskylä.
Lüdwig, G.X., Alatalo, R.V., Helle, P., Linden, H., Lindsrom, J. \& Siitari, H. 2006. Short- and long-term population dynamical consequences of asymmetric climate change in Black Grouse. Proceedings of the Royal Society B 273: 2009-2016.

Lüdwig, G.X., Alatalo, R.V., Helle, P., Nissinen, K. \& Siitari, H. 2008. Large-scale drainage and breeding success in boreal forest grouse. Journal of Applied Ecology 45: 325-333.

O’Connel, A.F., Nichols, J.D. \& Karanth, K.U. 2011. Camera traps in animal ecology: Methods and Analysis. Springer, New York.

Rintamäki, P.T., Karvonen, E., Alatalo, R.V. \& Lundberg, A. 1999. Why do Black Grouse males perform on lek sites outside the breeding season. Journal of Avian Biology 30: 359-366.

Siitari, H., Alatalo, R.V., Halme, P., Buchanan, K.L. \& Kilpimaa, J. 2007. Color signals in the Black Grouse (Tetrao tetrix): signal properties and their condition dependency. American Naturalist 169: supplement 81-92.

Swann, D.E., Hass, C.C., Dalton, D.C. \& Wolf, S.A. 2004. Infrared-triggered cameras for detecting wildlife: an evaluation and review. Wildlife Society Bulletin 32: 357-365.

Swenson, J. \& Angelstam, P. 1993. Habitat separation by sympatric forest grouse in Fennoscandia in relation to boreal forest succession. Canadian Journal of Zoology 71: $1303-1310$.

Received 14 September 2013. Accepted 3 March 2014 